\title{
MARX E A POLITECNIA, OU: do princípio educativo ao princípio pedagógico
}

\author{
Antônio Carlos Maciel ${ }^{1}$
}

\section{RESUMO}

Este artigo tem por objetivo expor a trajetória epistemológica da definição do conceito de politecnia como princípio pedagógico e explicar porque é o fundamento determinante da educação integral politécnica. Analisa a concepção marxiana de educação comparando as versões em língua francesa, inglesa, portuguesa e brasileira (MARX, 1976, 1982, 1983, 1996), bem como algumas das mais importantes obras brasileiras sobre o tema (SAVIANI, 1989, 2003, 2007; KUENZER, 1989, 2005; FRIGOTTO, 2002, 2012; SOARES, 2000, 2004; LOMBARDI, 2008; SANFELICE, 1991; NOGUEIRA, 1990; NOSELLA, 2004, 2007, 2009), passando por Manacorda (2010) para demonstrar a importância, mas, ao mesmo tempo, os limites do conceito de trabalho como princípio educativo. O resultado do estudo aponta para a necessidade de: a) atualizar a concepção marxiana de educação; b) complementar o trabalho como princípio educativo com a politecnia como princípio pedagógico; c) operacionalizar a prática pedagógica pela formulação da politecnia como princípio pedagógico; d) demonstrar a educação integral politécnica, da educação infantil à universidade, como alternativa às propostas pedagógicas de educação escolar estatal.

Palavras-chave: Politecnia. Princípio Educativo. Princípio Pedagógico.

\section{MARX AND POLYTECHNICS, OR: from the educational principle to the pedagogical principle}

\begin{abstract}
This article aims to elaborate on the epistemological trajectory of the definition of the concept of polytechnics as a pedagogical principle and to explain why it is the fundamental foundation of integral polytechnic education. It analyzes the Marxian conception of education comparing the French, English, Portuguese and Brazilian versions (MARX, 1976, 1982, 1983, 1996), as well as some of the most important Brazilian scholarly writings on the subject (SAVIANI, 1989, 2003, 2007; KUENZER, 1989, 2005; FRIGOTTO, 2002, 2012; SOARES, 2000, 2004; LOMBARDI, 2008; SANFELICE, 1991;

\footnotetext{
1 Pós-Doutor em Educação e Professor Titular da Universidade Federal de Rondônia. Professor de Metodologia da Pesquisa em Educação do Programa de Pós-Graduação Stricto Sensu em Educação da Universidade Federal de Rondônia e Coordenador do Grupo de Pesquisa Centro Interdisciplinar de Estudos e Pesquisas em Educação e Sustentabilidade CIEPES/HISTEDBR-UNIR. E-mail: maciel_ac@hotmail.com
} 
NOGUEIRA, 1990; NOSELLA, 2004, 2007, 2009) including Manacorda (2010) to demonstrate the importance, but at the same time, the limits of the concept of work as an educational principle. The result of the study points to the need to: a) update the Marxian conception of education; b) complement work as an educational principle with polytechnics as a pedagogical principle; c) operationalize pedagogical practice by the formulation of polytechnics as a pedagogical principle; d) present the polytechnic integral education, from kindergarten to higher education, as an alternative to the pedagogical proposals of state education.

Keywords: Polytechnics. Educational Principle. Pedagogical Principle.

\section{MARX Y LA POLITECNIA, O: del principio educativo al principio pedagógico}

\section{RESUMEN}

Este artículo tiene por objetivo exponer la trayectoria epistemológica de la definición del concepto de politecnia como principio pedagógico y explicar por qué es el fundamento determinante de la educación integral politécnica. Analiza la concepción marxista de la educación mediante la comparación de las versiones en francés, inglés, portugués europeo y brasileño (Marx, 1976, 1982, 1983, 1996), así como algunas de las obras más importantes de Brasil sobre el tema (SAVIANI, 1989, 2003, 2007; KUENZER, 1989, 2005; FRIGOTTO, 2002, 2012; SOARES, 2000, 2004; LOMBARDI, 2008; SANFELICE, 1991; NOGUEIRA, 1990; NOSELLA, 2004, 2007, 2009), pasando por Manacorda (2010) para demostrar la importancia, pero al mismo tiempo los límites del concepto de trabajo como principio educativo. El resultado del estudio apunta hacia necesidad de: a) actualizar la concepción marxista de educación; b) complementar el trabajo como principio educativo con la politecnia como principio pedagógico; c) hacer operativo la práctica pedagógica por la formulación de la politecnia como principio pedagógico; d) demostrar la educación integral politécnica, de la educación infantil a la universidad, como alternativa a las propuestas pedagógicas de educación escolar estatal.

Palabras clave: Politecnia. Principio Educativo. Principio Pedagógico.

\section{INTRODUÇÃO}

A concepção marxiana de educação tem sido vista como origem da educação politécnica soviética, como fundamento do trabalho como princípio educativo que, por sua vez, é fundamento de diversas concepções marxistas de educação emancipatória. Implicitamente, o que se depreende daí é uma busca incessante por encontrar um modo de operacionalizar princípios teóricos capazes de efetivar processos educativos, que buscassem a emancipação humana.

Experimentalmente, excetuando-se informações orais, de quem estudou ou viveu na antiga URSS, são escassas e muito recentes as obras que 
tratam da educação politécnica naquele país o que, até o presente momento, dificulta uma compreensão mais efetiva da relação entre um princípio teórico e uma prática pedagógica, em um lócus, onde a escola tivesse efetivamente o papel emancipador da própria sociedade, uma vez considerada socialista.

$\mathrm{Na}$ sociedade capitalista, a operacionalização do conceito de trabalho como princípio educativo, desde sua origem italiana até a extensa produção brasileira, tem ficado restrita a raras experiências pedagógicas e, mesmo assim, sem uma análise efetiva de sua operacionalização.

No mundo da ciência pedagógica, todos o sabem ou deveriam saber que, por decorrência de sua natureza teórico-prática, um princípio pedagógico encerra três dimensões: uma de natureza filosófica, a concepção de homem; outra, de natureza epistemológica, a concepção de educação; e, ainda, a de natureza metodológica, indicativa do fazer pedagógico.

Aqui, sustenta-se a hipótese de que o trabalho como princípio educativo atende às duas primeiras dimensões, mas não atende à terceira, origem da falta de análise sobre sua operacionalização que, efetivamente, não é possível, porque o princípio carece dessa dimensão. Para preencher essa lacuna é que se apresenta a politecnia como princípio pedagógico.

A definição desse conceito nasceu da necessidade de operacionalizar o princípio do trabalho educativo numa experiência pedagógica de educação integral, oportunidade na qual, em meio à prática pedagógica, o trabalho como princípio educativo, por tudo quanto já se tinha produzido até 2005, não oferecia elementos metodológicos efetivos, pela razão já apontada acima. Esse fator limitante do trabalho, como princípio educativo, possibilitou não somente a emergência da politecnia, como princípio pedagógico, mas também a inserção da educação integral, por toda a extensão da educação escolar (da educação infantil ao ensino superior, e não só restrita ao Ensino Médio), como o lócus por excelência de sua realização. Expor esse processo, tendo 
por base os estudos sobre a concepção marxiana de educação, é o que se pretende com esse artigo.

\section{DOS LIMITES DO TRABALHO COMO PRINCÍPIO EDUCATIVO}

A concepção de trabalho como princípio educativo decorre da concepção marxiana de educação. Não tendo produzido especificamente um trabalho sobre educação, essa concepção aparece esparsa na obra marxiana (MANACORDA, 2010, p. 25, 37-39; MORAES, 1983, p. 2, 13-14), porém, nas "Instruções" de 1866 se encontram a elaboração mais sistemática acerca do tema, e é nesta obra, onde se buscará a concepção marxiana de educação. Ali, Marx (1976, p. 179) é enfático:

Par éducation, nous entendons trois choses: 1. éducation intellectuelle; 2 . éducation corporelle, telle qu'elle est produite par les exercices gymnas-tiques et militaires; 3 . éducation technologique, embrassant les principes généraux et scientifiques de tous les procès de production, et en même temps initiant les enfants et les adolescents au maniement des instruments élémentaires de toutes les branches d'industrie? .

Parece objetivo que esta concepção se sustenta sobre três alicerces: o intelectual, que é formado pela aquisição do conhecimento científico e cultural; o corporal, enquanto desenvolvimento físico; e, o tecnológico, enquanto domínio de princípios gerais necessários ao manejo dos diversos ramos industriais. O problema é que, na sequência do raciocínio, após reafirmar a importância da indissociabilidade entre educação intelectual, educação corporal e educação tecnológica, Marx (1976, p. 179) substitui o termo technologique por polytechnique: "Cette combinaison du travail productif, payé avec l'éducation intellectuelle, les exercices corporels et la formation polytechnique [...]", gerando divergências entre seus intérpretes brasileiros, mas quais as razões?

\footnotetext{
2 Optou-se pela versão francesa, por estar coerente com a tradução brasileira adotada nesta interpretação (MARX, 1983, p. 60; LOMBARDI, 2008, p. 12; SAVIANI, 2003, p. 144-146), em detrimento da de Nogueira (1990, p. 148), Manacorda (2010, p. 48), bem como da versão portuguesa Marx (1982, p. 6) e da inglesa (1996, p. 8). Esta última não deixa de alertar, no entanto, sobre a expressão "technological training": "The German text calls this 'polytechnical training'".
} 
Em primeiro lugar, a interpretação brasileira sobre a temática decorre da interpretação italiana de Marx, via Gramsci e Manacorda, o que se, de um lado, proporciona relativa uniformidade interpretativa sobre alguns pontos, de outro, um desconforto hermenêutico, em face da divergência sobre outros. Um desses pontos é exatamente o que se refere ao entendimento do conceito politecnia.

Manacorda, por carta a Soares (2004, p. 4), em resposta a missiva desta a ele solicitando entrevistá-lo, chega a admitir que tenha parte da responsabilidade pela confusão: "De fato, creio que seja também eu, talvez junto a Dermeval Saviani, responsável por essa confusão"3. Soares (2004, p. 5) adverte, contudo, que mesmo a entrevista de Manacorda não esclarece suficientemente a problemática, a partir do que passa a fazê-lo, sem, no entanto, definir exatamente o que vem a ser politecnia para ela, pelo menos nesse texto (SOARES, 2004, p. 5-7) ${ }^{4}$.

Nosella (2007) é radicalmente contrário à associação do termo politecnia como fundamento da concepção marxista de educação, por três razões (p. 141-146) e, novamente referindo-se à "confusão", sobre a qual o próprio Manacorda pede desculpas, prefere o termo "tecnológico" ao de politecnia (p. 144). Mas não deixa de destacar: "É evidente que Marx utiliza os dois termos" (p. 144), e passa a justificar a opção pelo termo "tecnológico", fundamentando-se em Manacorda, justificando sua preferência por este em detrimento daquele. Sobre a polêmica, assim se manifesta Saviani (2003, p. 145):

[...] para além da questão terminológica, isto é, independentemente da preferência pela denominação "educação tecnológica" ou

3 Ao apresentar Projeto de Pesquisa de Pós-Doutorado "Do Trabalho como Princípio Educativo à Politecnia como Princípio Pedagógico da Educação Integral" (Atividades Programadas de Pesquisa em sessão acadêmica do HISTEDBR, Faculdade de Educação da UNICAMP, em abril de 2015), O Professor Saviani discordou da corresponsabilidade, chamando atenção para o fato de que o próprio Manacorda, ao assinalar o termo "talvez", não tem certeza.

4 Entretanto, a definição do conceito, em seu contexto histórico de surgimento, fica bem clara em Soares (2000, p. 337-38, 341-43, 351-52, 363-371), quando mostra a contribuição de Lênin/Krupskaia, aproximação desta com a interpretação gramsciana, bem como o distanciamento tanto do stalinismo e da "escola do trabalho", quanto do escolanovismo deweyano. 
"politécnica", é importante observar que, do ponto de vista conceitual, o que está em causa é um mesmo conteúdo. Trata-se da união entre formação intelectual e trabalho produtivo, que, no texto do Manifesto, aparece como "unificação da instrução com a produção material", nas Instruções, como "instrução politécnica que transmita os fundamentos científicos gerais de todos os processos de produção" e n' O Capital, como "instrução tecnológica, teórica e prática".

Com esse entendimento e, desde logo, o adotado aqui, Saviani dá por encerrada a discussão, justificando, porque, ao contrário de Nosella e Manacorda5, que utilizam o termo tecnologia, adota o termo politecnia, sendo parte, inclusive, da proposta leninista de educação, tal como ele próprio atesta (2003, p. 45-46), além de Soares (2004, p. 5 e 2000, p. 363-371), Nosella (2007, p. 146), Freitas (2005, p. 291-293), Manacorda (2010, p. 202203).

Para tanto, todavia, a compreensão de politecnia como "união de formação intelectual e trabalho produtivo" (SAVIANI, 2003, p. 145) é insuficiente: primeiro porque reduzida a essa união, politecnia tem o mesmo sentido de trabalho educativo; segundo porque este, enquanto princípio extraído da concepção marxiana de educação, não abrange o desenvolvimento físico, tal como na concepção original; e, finalmente, porque, hoje, outras dimensões são tão fundamentais à emancipação humana, quanto as três originais.

Além disso, com raríssimas exceções, os autores, que aparentemente exauriram essa discussão no Brasil, vinculados ou não, ao Grupo Trabalho e Educação da ANPED, ou trataram "o trabalho como princípio educativo" como fundante da natureza humana e, portanto, como princípio geral da condição humanizante do trabalho (SAVIANI, 2003, p. 132-133; FRIGOTTO, CIAVATA e RAMOS, 2013, p. 02), ou reduziram a concepção de "trabalho como princípio educativo" a um processo de união entre educação e trabalho a ser operado no ensino médio e nos cursos profissionais e técnicos (SAVIANI, 1989, p. 12, 2003, p. 136 e 2007, 160; KUENZER, 1989, p. 23;

\footnotetext{
5 Ver a propósito em Manacorda (2010, p. 49, 51, 52, 58, 202-203) e Nosella (2009, p. 17), este último, todavia, em muitas passagens, deixa a entender que uma e outra se equivalem (NOSELLA, 2004, p. 35, 181, 182, 184, 185).
} 
MACHADO, 1991, p. 60; FRIGOTTO, CIAVATA e RAMOS, 2012, p. 41-46; 2013, p. 7-8).

No primeiro caso, concorda-se plenamente; no segundo, trata-se de uma redução inapropriada da concepção marxiana.

Portanto, ainda que em seus pressupostos a compreensão de trabalho como princípio educativo envolva o amplo espectro da formação humana, na aplicação aos processos educacionais concretos, essa compreensão se faz reduzida ao ensino médio. Como, então, estendê-la, com propriedade, para toda a trajetória dos graus da educação escolar? Como ampliá-la para envolver as diversas dimensões humanas? Além disso, como essa concepção do segundo caso atribui ao trabalho como princípio educativo o mesmo significado de politecnia, como desfazer essa incompreensão?

Cabe, então, demonstrar, pois há amadurecimento conceitual para tanto, que a politecnia é um princípio pedagógico orientador da prática educativa em todos os níveis da educação escolar. Que a politecnia como princípio pedagógico não é sinônimo de trabalho como princípio educativo, embora decorra deste. Por decorrência, a politecnia como princípio pedagógico se sustenta em múltiplas dimensões educativas, as quais correspondem às dimensões humanas e, ipsu facto, o lugar privilegiado de sua concretização é a educação integral.

Por contraditório que pareça, praticamente, todos os autores que, ou reduzem a concepção marxiana de educação (seja pela simplificação trabalho/educação, seja pela aplicação ao Ensino Médio) ou atribuam identidade entre trabalho como princípio educativo e politecnia, dão pistas significativas para a sua aplicação em toda a trajetória e em todas as dimensões da educação escolar.

O próprio Saviani não só aponta as possibilidades de a politecnia fundar os processos educativos escolares, da escola elementar até a universidade (SAVIANI, 2007, 159-162), mas também do trabalho como princípio educativo, segundo ele: "Pode-se, pois, dizer que o currículo escolar, desde a escola elementar, guia-se pelo princípio do trabalho como 
o processo através do qual o homem transforma a natureza" (SAVIANI, 2003, p. 135).

Corroborando com essa posição Frigotto (2002, p. 14) assinala: "O trabalho [...] por ser elemento criador da vida humana [...] constitui-se em um dever a ser apreendido, socializado, desde a infância". Com Ciavata e Ramos, Frigotto (2013, p. 7) deixa claro que a politecnia deve ser fundamento da educação básica "em suas diferentes etapas".

Essas pistas foram o detour para que a definição do conceito "politecnia como princípio pedagógico" não se restringisse a um grau determinado de ensino.

Por outro lado, a concepção de desenvolvimento das múltiplas capacidades humanas, por intermédio da educação escolar é preconizada tanto por Saviani (2003, p. 140), enquanto desenvolvimento onilateral, quanto por Machado (1994, p.19), que assim se expressa:

Politecnia representa o domínio da técnica em nível intelectual e a possibilidade de um trabalho flexível com a recomposição de tarefas a nível criativo. Supõe a ultrapassagem de um conhecimento meramente empírico, ao requerer o recurso a formas de pensamento mais abstratas. Vai além de uma formação simplesmente técnica ao pressupor um perfil amplo de trabalhador, consciente, capaz de atuar criticamente em atividade de caráter criador e de buscar com autonomia os conhecimentos necessários ao seu progressivo aperfeiçoamento.

Na mesma linha de raciocínio Kuenzer (2005, p. 89), se expressa, afirmando que "A politecnia supõe, portanto, uma nova forma de integração de vários conhecimentos, através do estabelecimento de ricas e variadas relações que quebram os bloqueios artificiais que transformam as disciplinas em compartimentos específicos [...]".

Por fim, é importante frisar, que não se trata de transformar o conceito trabalho como princípio educativo em trabalho como princípio pedagógico, tal como propõe Nosella (2009, p. 10-11):

A expressão "trabalho como princípio educativo" se refere ao grande debate desencadeado entre pedagogistas a partir da revolução industrial, quando o trabalho industrial foi apontado como principal contexto e referência educacional da sociedade. A tese deste texto 
me levou a preferir o termo "pedagógico", pois se o princípio educativo se aplica indistintamente a todo o sistema escolar, o princípio pedagógico caracteriza a especificidade metodológicoescolar de cada fase do ensino. Assim, "princípio educativo" não é sinônimo de "principio pedagógico": o primeiro é um conceito mais amplo que se aplica a todo o processo educativo, o segundo é a especificidade pedagógica que diferencia cada etapa do sistema escolar.

Embora, aqui, nesta citação de Nosella, encontre-se a outra pista decisiva para a diferenciação conceitual entre educativo e pedagógico: o primeiro aplica-se "a todo o sistema escolar"; o segundo, aos processos metodológicos escolares. No primeiro caso, é oportuno acrescentar: escolares e não escolares; no segundo, não somente aos processos metodológicos escolares, mas a todos os processos educativos escolares.

Se assim é, caberia perguntar: por que os autores citados se limitaram ao ensino médio e a algumas dimensões do desenvolvimento das faculdades humanas, quando tratam de operacionalizar os conceitos ou de elaborar propostas concretas de ensino?

Sanfelice (1991, p. 71-72) já, em 1989, no Seminário "Propostas para o ensino médio na nova LDB", perguntava: "Uma concepção coerente de politecnia poderia restringir-se a esta educação básica, excluindo $\circ 3^{\circ} \mathrm{grau}$ [...]?". E arremata de forma inequívoca: "[...] como é possível entender que um determinado nível de ensino seja o responsável por esta tarefa e não o sistema educacional como um todo?".

Por outro lado, como não vê que a concepção de politecnia, que se propõe à formação onilateral do homem (SAVIANI, 2003, p. 149), para além de ser simplesmente uma possibilidade de superação da divisão intelectual e manual do trabalho, seja a condição para a formação integral e, portanto, para o desenvolvimento das múltiplas capacidades humanas (LOMBARDI, 2008, p. 8-15)?

Particularmente, pensa-se que faltou aos autores, que reduziram tanto a compreensão conceitual do trabalho como princípio educativo, quanto à politecnia ao Ensino Médio, aplicar suas criações conceituais a uma experiência pedagógica concreta, tal como ocorreu com a experiência 
pedagógica do Projeto Burareiro de Educação Integral, durante dezenove meses, entre janeiro de 2005 e agosto de 2006, como laboratório experimental de uma concepção de educação integral.

Foi esse laboratório experimental, que proporcionou a definição do conceito politecnia como princípio pedagógico, aplicável a toda a trajetória da educação escolar, da Educação Infantil à universidade, como princípio orientador do desenvolvimento das múltiplas dimensões humanas, fundamentado pelas noções de omnilateralidade e emancipação, para se tornar, a partir disto, um conceito pedagógico operacional, cujo lugar, por excelência, é a educação integral.

\section{A POLITECNIA COMO PRINCÍPIO PEDAGÓGICO FUNDAMENTAL DA EDUCAÇÃO INTEGRAL 6}

Concordando com Saviani, desde já parece evidente que educação tecnológica ou politécnica, em Marx, é apenas uma das três dimensões daquela concepção de educação, logo não se pode reduzir a concepção marxiana de educação a esta dimensão. Por consequência, desde Marx, a concepção de educação é mais ampla e envolve necessariamente a educação intelectual e corporal, o que a distingue, segundo o próprio Marx, da concepção burguesa de educação7.

Dessa maneira, o locus privilegiado, em termos de educação escolar, não é apenas o campo do Ensino Médio, mas todo o processo de formação educacional, da Educação Infantil ao Ensino Superior.

A politecnia como princípio pedagógico parte, portanto, das limitações expressas pela concepção de trabalho como princípio educativo8.

\footnotetext{
6 Parte da concepção apresentada aqui se encontra em Maciel, Jacomeli e Brasileiro (2017, p. 473-488).

7 Vale notar que o fato de a concepção marxiana se distinguir da concepção burguesa de educação, não impediu de o próprio Marx reconhecer que parte exatamente dela para construir a sua.

8 A sequência das figuras das ilustrações 1 e 2 possibilita acompanhar não somente 0 desenvolvimento da pesquisa sobre o trabalho como princípio educativo, iniciado em 2005 , com os estudos para a implantação do Projeto Burareiro de Educação Integral, no
} 
Num primeiro momento, trabalhou-se com a necessidade de acrescentar, dada a complexidade alcançada pelas forças produtivas no capitalismo contemporâneo e correspondentes formas de manutenção do status quo (imensuráveis instrumentos da sociedade civil e política), uma dimensão educativa, que explicitasse a necessária formação política, implícita nos textos marxianos acerca da educação.

Ora, a organização política das classes trabalhadoras é o meio pelo qual, do Manifesto do Partido Comunista, passando pela Primeira Internacional, a Associação Internacional dos Trabalhadores, até a Crítica ao Programa de Gotha, Marx e Engels veem como condição sine qua non os trabalhadores não lograriam transformar a sociedade capitalista.

Assim, parece plausível que se poderia acrescentar às três dimensões, uma quarta, a dimensão política, o que não deformaria aquela concepção original, num processo representado pela llustração 1.

Ilustração 1 - Concepção marxiana de educação: original (Figura 1) e ampliada (Figura 2)

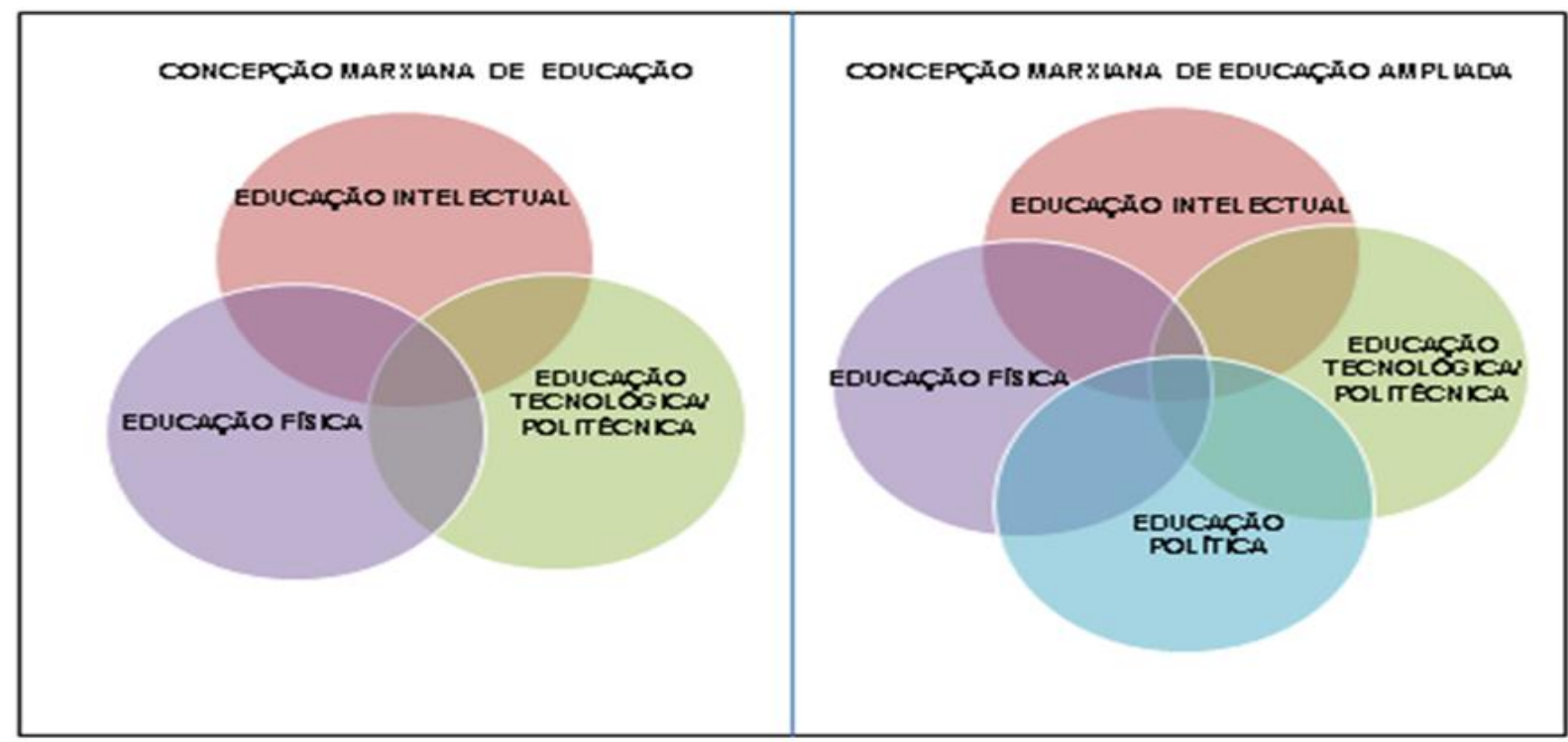

Fonte: Concepção do autor. Arte: Cintia Adélia da Silva.

Município de Ariquemes, estado de Rondônia, mas também o próprio processo de criação da politecnia como princípio pedagógico, a partir da concepção marxiana de educação, nos anos posteriores, num trabalho coletivo com os pesquisadores do Centro Interdisciplinar de Estudos e Pesquisas em Educação e Sustentabilidade - CIEPES/UNIR. 
Mas a sociedade capitalista tem imprimido, a si mesma, mudanças radicais, cada vez mais rápidas e profundas, que levaram os economistas, críticos dessa formação, a pensá-la por revoluções tecnológicas ou por paradigmas técnico-econômicos?. Dessa forma, de fins do século XIX aos dias de hoje, já se estaria quase no fim da terceira dessas grandes transformações, que ocorrem em todas as suas esferas: no controle da organização social, nas formas de Estado, governo e democracia, nos processos produtivos materiais, na produção de ciência e tecnologia. Conforme já se assinalou em outro texto, somente a natureza da sociedade não foi transformada, porque se aperfeiçoa sistematicamente, tanto em seus princípios, baseados na concentração hierarquizada da mais-valia, quanto em suas correspondentes formas de Estado, Governo e produção.

Ora, tais mudanças radicais, pela via do aperfeiçoamento, coloca à concepção marxiana de educação o desafio de acompanhar o desenvolvimento, tanto da ciência e da tecnologia, quanto da sociedade com suas múltiplas formas de reprodução material e de suas correspondentes formas de Governo, para propor alternativas educacionais viáveis, mesmo nas difíceis condições brasileiras, para as classes trabalhadoras. A formulação do princípio educativo do trabalho é uma conquista nessa perspectiva, mas ainda insuficiente.

Por consequência, não bastava acrescentar uma dimensão política ao conceito original, tratava-se de gerar um princípio pedagógico que, além de orientar a formação humana no sentido da onilateralidade e da emancipação (o que já é proporcionado pelo trabalho como princípio educativo), indo de encontro à formação unilateral e subserviente disponibilizada, pela burguesia, às classes trabalhadoras, fosse capaz de viabilizar metodologicamente um fazer pedagógico, que buscasse os fins da educação onilateral e emancipatória. Esse princípio é o da politecnia.

\footnotetext{
9 O conceito de paradigma técnico-econômico compreende o conjunto das formas e meios de produção caracterizados por uma dada revolução tecnológica, cujo ciclo se completa algo em torno de cinquenta anos - a onda de Kondratieff ou a long wave de Schumpeter. A esse respeito, consulte-se Perez (1984, p. 2-10); Guimarães (1993, p. 06); Lastres (1994, p. 4 e 16) e Galvão (1994, p. 04).
} 
A politecnia, não mais como uma dimensão particular de uma concepção, e sim como um princípio, a partir do qual os processos educativos pudessem buscar o desenvolvimento integral das múltiplas capacidades humanas, por meio de processos pedagógicos, que tratassem articuladamente cognoscibilidade, habilidade, sensibilidade e sociabilidade, tal com formulado por Maciel e Braga (2007, p. 61).

A cognoscibilidade 10 como desenvolvimento das dimensões lógicocognitivas e psíquicas (onde o conhecimento científico e tecnológico seja determinante); a habilidade, enquanto expressão de capacidades psicomotoras e físicas (onde o esporte e a formação profissionalizante constituam suportes fundamentais); a sensibilidade como potencialização de todos os sentidos (onde a música, a dança, a literatura, o teatro e as artes visuais, gráficas e plásticas tenham lugar privilegiado); e a sociabilidade enquanto efetivo exercício político da práxis social (onde a cidadania participativo-transformadora, a ecologia humana crítica e a saúde tenham prioridade).

A cognição, enquanto capacidade de entender e transformar a realidade exterior, não se desenvolveria sem os sentidos, sensores por intermédios dos quais a realidade exterior, em sua múltipla e complexa variedade histórico-natural, é transmitida para processamento no cérebro. Logo, cognição e sentidos, embora biologicamente distintos, constituem um complexo mecanismo de entendimento e transformação da realidade exterior, em cujo processo a própria cognição e sentidos são transformados.

O desenvolvimento recente da neurociência tem demonstrado o quanto a capacidade cognitiva depende das demais capacidades humanas, mas a sensibilidade enquanto potencialização de todos os sentidos, tem lugar privilegiado no processo de formação humana, porque é o elo que une o trabalho às outras dimensões humanas.

\footnotetext{
10 Vale ressaltar que, no texto original de 2005, tanto no próprio Projeto (MACIEL, 2016, p. 23), quanto nos textos publicados (MACIEL, BRAGA, 2007, p. 61; 2008, p. 206), o termo utilizado era "racionalidade" e não "cognoscibilidade". Este substituiu aquele, em virtude da sugestão de colegas, por ocasião da comunicação do trabalho "Projeto Burareiro: Politecnia e Educação Integral à Luz da Pedagogia Histórico-Crítica" no IV Simpósio Trabalho e Educação: Gramsci, Política e Educação, realizado pelo NETE/UFMG, em 2007, em Belo Horizonte (MACIEL, 2007, p. 4).
} 
Por isso, em se tratando de educação escolar, a negligência com essa dimensão leva, necessariamente, ao definhamento de múltiplas capacidades humanas, razão pela qual se postula para a música, a dança, a literatura, o teatro e as artes visuais, gráficas e plásticas, tratamento similar ao de outras dimensões humanas. De todo modo, tal negligência é uma forma de animalização humana ${ }^{11}$.

llustração 2 - Concepção marxiana de educação ampliada e atualizada (Figural) e a Politecnia como princípio pedagógico (Figura 2)

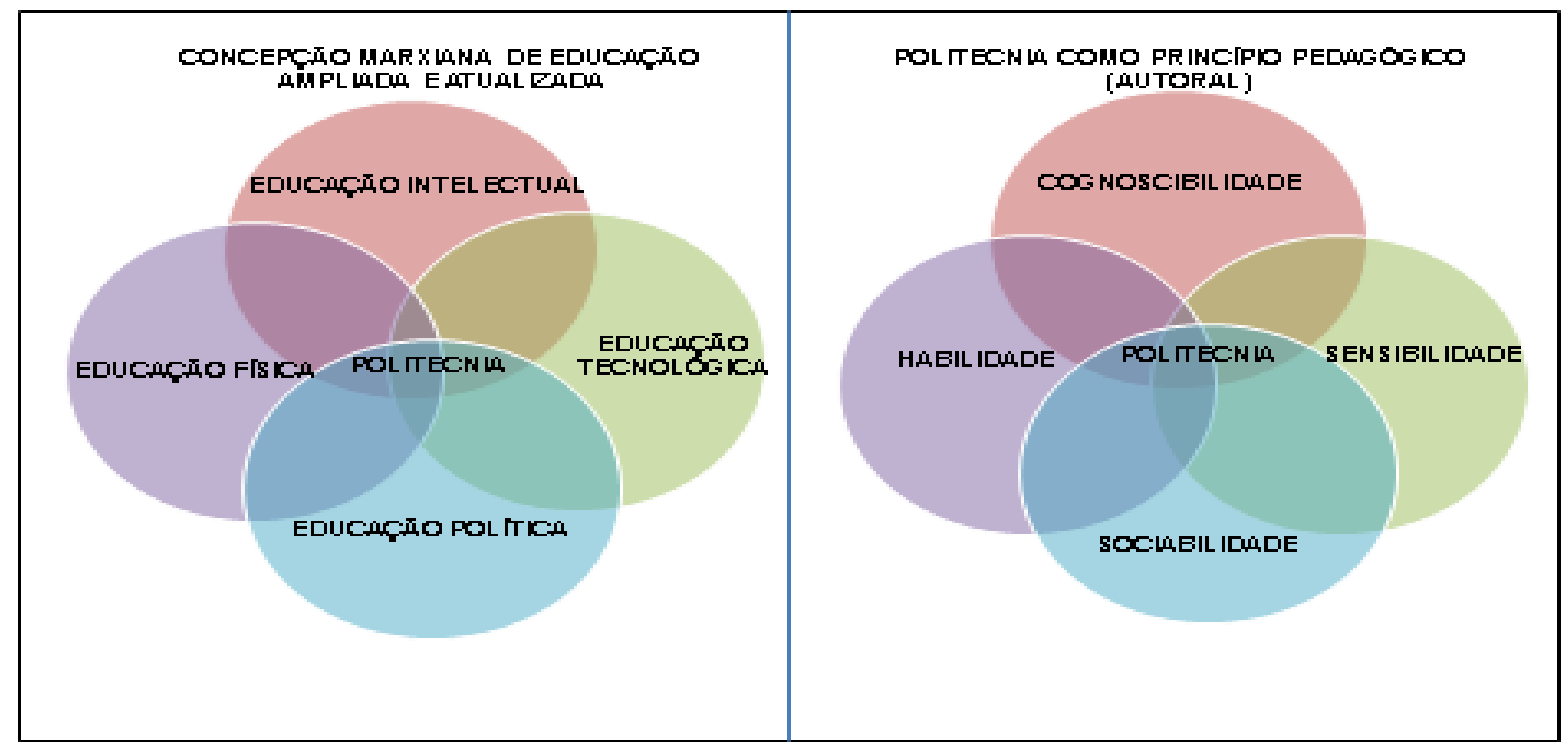

Fonte: Concepção do autor. Arte: Cintia Adélia da Silva.

\footnotetext{
11 Em uma passagem magistral dos Manuscritos Econômico-Filosóficos, Marx e Engels (1983, p. 33) assevera: "O homem apropria sua essência universal de forma universal, isto é, como homem total. Cada uma de suas relações humanas com o mundo (ver, ouvir, cheirar, degustar, sentir, pensar, observar, perceber, desejar, atuar, amar), em resumo, todos os órgãos de sua individualidade [...] são, em seu comportamento objetivo, em seu comportamento desde o objeto, a apropriação deste. [...] A propriedade privada nos tornou tão estúpidos e unilaterais que um objeto somente é nosso quando o temos, quando existe para nós enquanto capital ou quando é imediatamente possuído, comido, bebido, vestido, habitado; em suma, utilizado por nós. [...] Em lugar de todos os sentidos físicos e espirituais apareceu, assim, o simples estranhamento de todos estes sentidos, o sentido de ter". Ora, em nenhuma outra passagem a concepção de omnilateralidade (ou de seu contrário) fica tão explicita, quanto aqui: a relação entre o objetivo e o subjetivo, a educação, enquanto fonte de aprendizagem, e o corpo, enquanto capacidade de apreensão (ou apropriação, como queira), expressa quão múltiplas são as dimensões humanas, somente passíveis de serem desenvolvidas por uma educação, que tenha por objeto esse fim, tal é o caso da educação integral politécnica.
} 
Portanto, a capacidade humana de entender e transformar a realidade exterior desenvolve a capacidade de entender e transformar a realidade interior, num processo ininterrupto de mútua dependência. E não só a cognição e os sentidos, mas também as habilidades e a sociabilidade o fazer-se histórico-cultural e, portanto, político.

As habilidades - quer pelo desenvolvimento físico e psicomotriz, quer pelo manejo de instrumentos materiais e imateriais - são constituídas pelo mesmo processo de interação entre o homem e o meio ambiente históriconatural, processo do qual emerge sua natureza histórico-cultural, logo, política, já que é uma produção social, resultado de relações sociais determinadas pelo desenvolvimento das forças produtivas, no interior do qual o nível de compromisso social de classe é um fator decisivo, daí a importância do conceito sociabilidade.

Sociabilidade, enquanto compromisso social de classe resultante da organização política das classes subalternas, por meio da qual a consciência de classe seja um horizonte efetivo no transcurso de formação da força de trabalho, onde as lutas cotidianas por trabalho e melhores condições de habitação, estudo, saúde e alimentação exercem papel determinante de seu ser social. Numa palavra: organização e ação como práxis da consciência de classe.

Politecnia, portanto, é o princípio pedagógico que se fundamenta na concepção de que o homem é um ser histórico-cultural, constituído a partir de sua práxis social, cuja consequência é o desenvolvimento potencial ${ }^{12}$ de múltiplas capacidades cognitivas, sensíveis, físicas e sociais determinantes de sua humanização integral.

Tal formulação encontra seu locus de excelência na educação integral de tempo integral em espaço educativo adequado, e por quê? Porque, de um lado, somente a educação integral13, por seus objetivos

\footnotetext{
12 No processo ensino-aprendizagem é tamanha a importância do diagnóstico das potencialidades do educando, seja criança (TEIXEIRA, 2017, p. 50-53), seja jovem ou adulto (MACIEL, BRAGA, 2008, p. 204-206).

13 Na conferência "A Escola Pública Frente às Políticas de Educação Integral: Alternativas à Crise Política Brasileira Atual", Proferida no IV Encontro Estadual da ANPAE - Seção
} 
formacionais, pode almejar ao desenvolvimento das capacidades humanas em suas múltiplas dimensões, quer sejam cognitivas e físicas, quer sejam sensíveis ou sociais ${ }^{14}$, processo fundamental para se caminhar em direção à onilateralidade e à emancipação. De outro lado, uma educação que vise ultrapassar os limites da dimensão cognitiva, dadas as condições curriculares, de carga horária e de infraestrutura física e pedagógica da escola pública brasileira, com raríssimas exceções ${ }^{15}$, prescinde de tempo e espaços educativos compatíveis com a formação integral, por qualquer modalidade de educação integral (ainda que seja procedente: na modalidade de tempo integral, o tempo proporcione melhores condições de desenvolvimento).

Pelo processo politécnico de educação integral, ficou comprovado 16 que o trabalho pedagógico, organizado de forma coletiva, mas com liderança e direção para fins bem determinados, é plenamente viável, o que não é nenhuma novidade, haja vista muitas experiências educacionais nesse sentido.

Quando se trata de direcionar os processos pedagógicos para os fins educativos, de modo a articular as quatro dimensões da politecnia, então, vem à tona a imensa necessidade de conhecimento teórico, tempo e espaços educativos, posto que na escola pública brasileira, a carga horária exígua, a inexistência ou insuficiências de espaços educativos, a tradição pedagógica voltada eminentemente para o desenvolvimento cognitivo, a

Amazonas, em outubro de 2017,o autor classifica as experiências de educação integral em três modalidades: tempo integral, educação integral e educação integral politécnica, de acordo com o fundamento epistemológico, a finalidade pedagógica, a finalidade políticoideológica e a pedagogia dominante, exemplificando com as experiências pedagógicas brasileiras correspondentes a cada uma delas (MACIEL, 2017).

${ }_{14}$ Cada modalidade de educação integral, coerente com seu fundamento epistemológico e sua finalidade pedagógica, possui sua proposta de formação integral. No caso da educação integral politécnica, os meios pelos quais se pode alcançar a omnilateralidade e a emancipação são constituídos pelos processos pedagógicos, que visam o desenvolvimento articulado das dimensões cognitivas, físicas, sensíveis e sociais, conforme se encontra na definição de politecnia como princípio pedagógico.

15 É o caso dos Centros Educacionais de Tempo Integral (CETIs) de Manaus, tal como comprova o trabalho de Silva (2017).

16 Todos os dados de comprovação se baseiam no Laboratório Social do Projeto Burareiro de Educação Integral. Ver a propósito Maciel e Braga (2007), Maciel, Braga e Ranucci (2016) e Maciel $(2007,2016)$. 
formação docente especializada, juntos concorrem, como grandes obstáculos, à implementação da educação integral, em particular, a politécnica. Por isso, no Laboratório do Burareiro, a superação de alguns desses obstáculos, já foi suficiente para que a escola apresentasse um desempenho diferenciado frente às demais escolas do município.

\section{CONCLUSÃO}

\section{INCÔMODOS EPISTEMOLÓGICOS NA ACADEMIA: estaria a pedagogia condenada por sua natureza teórico-prática?}

Em Congressos, Simpósios e Encontros por onde se tem apresentado o princípio pedagógico da politecnia parece causar mal-estar o fato de que se expõe esse princípio como produto de uma experiência pedagógica que, além de ter servido como laboratório experimental (outro termo amaldiçoado) para a definição do conceito, serviu, também, para perceber limites de um conceito, tão formalmente aceito como definitivo por parte da academia filiada à tradição marxiana, como é o caso do trabalho como princípio educativo.

Traz-se para esta conclusão esse incômodo: a Pedagogia é ou não é ciência? Se for, qual sua natureza? Para aqueles que se colocam no campo da modernidade, a negligência com as questões da ação e prática pedagógicas, bem como da experimentação pedagógica, abrem dois flancos epistemológicos, que precisam de consistência: de um lado, não sendo ciência moderna, só poderia ser filosofia; sendo filosofia, seus princípios não precisam ser comprovados pela prática social e, assim, os pós-modernos teriam razão por levantarem as mais diversas impossibilidades da ciência moderna. De outro, sendo ciência, comprovações da efetividade, na prática social, de seus princípios são imprescindíveis à constituição de uma epistemologia específica, que a constitua como tal, tanto quanto outras ciências humanas.

Ora, o corpus epistemológico de uma ciência é uma construção histórica, cujo desenvolvimento, necessariamente, deve acompanhar as mudanças estruturais de seu objeto para que não se torne obsoleto. 0 
acompanhamento da relação conceito/realidade se faz ou pela atualização (inovação incremental para uns; mudança quantitativa para outros) das definições de um conceito ou pela refutação desse conceito (inovação radical para uns; mudança qualitativa para outros).

Por essa lógica, embora seja esperada a resistência à mudança pela ortodoxia do dogmatismo reificante, a construção epistemológica de uma ciência ou de uma teoria, que se coloque no âmbito desta, não se faz sem tais mudanças, ampliando, aprofundando e atualizando definições conceituais em função das mudanças operadas em seu objeto de estudo.

É esse o espírito que tem guiado as pesquisas sobre a concepção marxiana de educação, a decorrente formulação do trabalho como princípio educativo, a proposição não só da politecnia como princípio pedagógico, mas também da educação integral politécnica.

Espera-se, que se tenha deixado claro não ser possível conceber a proposta marxiana de educação sem seus três fundamentos originais, que o desenvolvimento físico, quer como saúde corporal, quer como destreza laboral, é imprescindível à formação humana como um todo e, por isso mesmo, não pode ser descolado da relação trabalho educação.

Que, embora Marx (e Engels) não seja explícito sobre a formação política das classes trabalhadoras nas Instruções aos Delegados de 1866; é contundente nos textos sobre o imperativo de transformação da sociedade capitalista (MARX, ENGELS, 1974, 1998; MARX, 1979a, 1979b; ENGELS, 1978) donde se deduz a necessidade de explicitar essa quarta dimensão da concepção marxiana de educação.

Assim, além de acrescentar, portanto, um quarto fundamento à concepção marxiana de educação, ampliando-a explicitamente, os estudos apontaram a necessidade de intervir na discussão brasileira sobre as razões que levaram Marx a utilizar dois termos para a mesma dimensão educativa.

O resultado tanto teórico, quanto empírico (aplicação no Projeto Burareiro de Educação Integral) foi a descoberta dos limites do conceito "trabalho como princípio educativo". 
Do ponto de vista teórico, esses limites dizem respeito tanto à simplificação da concepção marxiana de educação (restrita à relação educação/trabalho), quanto à redução de sua aplicação (restrita ao Ensino Médio).

Do ponto de vista empírico, esses limites dizem respeito à insuficiência pedagógica decorrente de o trabalho como princípio educativo não ir além de suas próprias determinações filosóficas e epistemológicas, encerrando seu alcance conceitual à concepção de homem e de sociedade direcionado pelo ideal socialista.

A pedagogia e a prática pedagógica, para existirem enquanto tal, precisam ir ultrapassar tais limites. Para ir além, no patamar em que se encontra a discussão no Brasil, não havia outro caminho senão o de enfrentar o consagrado princípio do trabalho educativo.

E de há muito, como se pensa ter demonstrado, vários autores indicavam o caminho: o imbróglio da utilização dos termos politécnica/tecnologia já houvera sido solucionado por Saviani, restava, então, fazer a síntese das discussões sobre a concepção marxiana de educação, sem transgredir, por assim dizer, a ortodoxia dos termos expressos na concepção original.

Mas havia um problema conceitual de fundo: no Brasil, não raramente, os autores interpretam que a concepção marxiana de educação significa trabalho como princípio educativo, quando não é. Este decorre daquela, e decorre, como se demonstrou, suprimindo a dimensão física, corporal.

Assim, tendo por base os textos nos quais Marx expõe as múltiplas dimensões humanas (ver, ouvir, cheirar, degustar, sentir, pensar, observar, perceber, desejar, atuar, amar - conforme nota 11) e, na medida em que omnilateralidade é exatamente esse desenvolvimento múltiplo completo, e que o único dos termos originais utilizados para exprimir essa concepção de educação é o termo politecnia, este foi transformado no termo fundamental da concepção marxiana de educação, tal como está ilustrada pela figura onde essa concepção aparece ampliada e atualizada (llustração 2, Figura 1). 
Esta reestruturação da concepção marxiana de educação se é ortodoxa quanto à utilização dos termos, é inteiramente não ortodoxa quanto à concepção e definição do termo politecnia. Enquanto concepção, politecnia passa a ser um princípio sobre o qual se sustentam as dimensões intelectual, física, tecnológica lagora inteiramente separada de politecnia) e política; enquanto definição, politecnia é o princípio pedagógico, que visa orientar os processos educativos a buscar 0 desenvolvimento das dimensões intelectual, física, tecnológica e política, desenvolvimento esse que, em seu conjunto, é o desenvolvimento da omnilateralidade humana, por cujo processo está associado a emancipação humana.

Esta é a trajetória sobre a qual repousa a proposta de atualização da concepção marxiana de educação.

O problema é que, tal atualização, torna mais evidente a diferença conceitual entre a concepção marxiana de educação e o trabalho como princípio educativo. Se este, como se viu, já simplificava e reduzia a concepção original, por esta perspectiva, ampliada e atualizada, se distanciava ainda mais. Isso estava a significar que o trabalho como princípio educativo deveria ser descartado?

Claro que não. O trabalho como princípio educativo, enquanto princípio filosófico e epistemológico, é um fundamento conceitual historicamente atual e indispensável à práxis educativa, mas carece de uma dimensão pedagógica, que o compatibilize com a concepção marxiana de educação, de um lado, e de outro, proporcione instrumentos pedagógicos indispensáveis a um tipo de ensino-aprendizagem, que busque, por meio da prática pedagógica, escolar e não escolar, o desenvolvimento da omnilateralidade e da emancipação humanas.

Essa dimensão capaz de complementar o trabalho como princípio educativo, que o compatibilize inteiramente com a concepção marxiana de educação e operacionalize a prática pedagógica, foi definida pelos estudos, ratificada pela experiência do Projeto Burareiro de Educação Integral, pela formulação da politecnia como princípio pedagógico. 
Ora, a politecnia como princípio pedagógico, pela atualização da concepção marxiana de educação, tal como exposta aqui, sem transgredir os termos originais, está formulada. Caberia perguntar: dadas as transformações do mundo produtivo capitalista, do consequente aperfeiçoamento de controle das instituições do Estado liberal, do aprofundamento do conhecimento científico nas ciências que dão suporte à pedagogia, aquela formulação original, mesmo ortodoxamente atualizada, é uma base conceitual suficientemente consistente, a partir da qual se possa responder às demandas das classes trabalhadoras no contexto atual da sociedade capitalista?

A resposta é não. No século, que separa o contexto no qual fora elaborado "O Capital" do que emerge a produção eletrônica informatizada, entre tantas transformações nos processos produtivos, acontece uma, pouco discutida, que consiste no fato de que a produção industrial baseada na progressiva divisão técnica do trabalho em função da capacidade de adestramento do trabalhador se esgota para dá lugar à progressiva reunificação da divisão técnica do trabalho, baseada na microeletrônica informatizada, em função de habilidades do trabalhador adquiridas por meio de conhecimento técnico, de médio e alto grau de complexidade. Numa palavra: a lógica do processo produtivo foi invertida! E esta inversão se encontra no centro nervoso do papel da escola e do tipo de educação que se pretende oferecer, pelo referencial teórico no qual os marxistas se apoiam.

No mesmo diapasão se encontram as transformações operadas nas instituições do Estado burguês. A transição do Estado liberal clássico para o Welfare State, e deste para o neoliberal não consiste apenas numa mudança terminológica, trata-se de um vigoroso reaparelhamento sincronizado, no qual esquemas clássicos como sociedade civil, sociedade política, sociedade econômica, infraestrutura econômica e superestrutura política, jurídica e ideológica não conseguem, sem aprofundamento, explicar, dada a interdependência das estruturas e, não raramente, a inversão das determinações. 
Para complicar, no caso brasileiro, a instauração do estado democrático de direito, e não de direito democrático, construído por uma maioria conservadora e por uma minoria reformista, que chegou a governar o país sob uma suposta bandeira de esquerda, eleva a graus impensáveis as dificuldades de explicação da realidade social e política. Numa palavra: perdeu-se subitamente a capacidade de distinguir o Estado liberal de outro, a democracia liberal de outra.

Por fim, o conhecimento científico das ciências que dão suporte à pedagogia, além do próprio desenvolvimento desta, tem progredido assustadoramente, no mesmo intervalo de tempo referido acima.

Para citar dois exemplos: neurociência tem demonstrado a interrelação entre o desenvolvimento cognitivo, a nutrição, as habilidades neuromotoras, estre as quais as diversas formas de sensibilidade; por seu turno, a genética, por meio dos estudos do genoma, tem chegado, cada vez mais, à conclusão de que o aparecimento das características humanas diferenciadoras dos genes humanos para os primatas decorreram das necessidades culturais de sobrevivência.

Assim, consideradas as profundas transformações no mundo da produção industrial (e nos demais setores produtivos aquém e além deste), na organização da sociedade e do Estado que a regulamenta e no desenvolvimento científico e tecnológico, não há como não pensar a educação, sem essas transformações e as conquistas da ciência.

Sem medo dos riscos e das críticas, politecnia como princípio pedagógico tenta dar um pequeno passo nessa direção ao mostrar uma possibilidade de atualização da concepção marxiana de educação e alguns limites do trabalho como princípio educativo. Além disso, por essa via interpretativa propõe a educação integral politécnica, da educação infantil à universidade, como alternativa às propostas pedagógicas de educação escolar estatal. 


\section{REFERÊNCIAS}

ENGELS, F. Del socialismo utópico al socialismo científico. Moscú-URSS: Editorial Progreso, 1978.

FREITAS, F. M. de C. Lenin e a educação política: domesticação impossível, resgate necessário. 2005. 309 f. Tese (Doutorado em Educação) - Faculdade de Educação, Universidade Estadual de Campinas-SP, Campinas, SP.

FRIGOTTO, G. A dupla face do trabalho: criação e destruição da vida. In: FRIGOTTO, G.; CIAVATTA, M. (Orgs.). A experiência do trabalho e a educação básica. Rio de Janeiro: DP\&A, 2002. p. 11-27.

FRIGOTTO, G.; CIAVATA, M.; RAMOS, M. N. A gênese do Decreto 5.154/2004: um debate no contexto controverso da democracia restrita. In: FRIGOTTO, G.; CIAVATA, M.; RAMOS, M. N. (Orgs.). Ensino médio integrado: concepções e contradições. 3. ed. São Paulo: Cortez, 2012. p. 21-56.

FRIGOTTO, G.; CIAVATA, M.; RAMOS, M. N. O trabalho como princípio educativo no projeto de educação integral de trabalhadores - excertos. Disponível em:

$<$ http://redeescoladegoverno. fdrh.rs.gov.br/upload/1392215839_O\%20TRABALHO\%20COMO\%2OPRINC\%C3\% 8DPIO\%20EDUCATIVO\%20NO\%20PROJETO.pdf>. Acesso em: 11 mar. 2013.

GALVÃO, A. C. Inovações e desenvolvimento: apontamento para pensar o caso brasileiro. Brasília: CNPq, 1994.

GUIMARÃES, A. O. Inovação e desenvolvimento econômico. In: VIOTT, Eduardo Baumgratz (Coord.). Dimensão econômica das inovações tecnológicas. Brasília: NPCT-UnB/ABIPTI/CNPq/ SEBRAE, 1993.

KUENZER, A. Z. O trabalho como princípio educativo. Cadernos de Pesquisa, São Paulo, n. 68, p. 21-28, fev. 1989.

KUENZER, A. Z. Exclusão includente e inclusão excludente: a nova forma de dualidade estrutural que objetiva as novas relações entre educação e trabalho. In: SAVIANI, D.; SANFELICE, J. L.; LOMBARDI, J. C. (Orgs.). Capitalismo, trabalho e educação. 3. ed. Campinas, SP: Autores Associados, 2005. p. 77-95.

LASTRES, H. M. M. Mudanças tecnológicas, paradigmas técnico-econômicos e tendências da nova estratégia competitiva industrial. Rio de Janeiro: CNPq, 1994.

LOMBARDI, J. C. Educação, ensino e formação profissional em Marx e Engels. In: SAVIANI, D.; LOMBARDI, J. C. (Orgs.). Marxismo e educação: debates contemporâneos. 2. ed. Campinas, SP: Autores Associados/HISTEDBR, 2008. p. 1-38.

MACHADO, L. R. S. Politecnia no ensino de segundo grau. In: BRASIL. Ministério da Educação. Secretaria Nacional de Educação Básica. Politecnia no ensino médio. Cadernos SENEB 5. São Paulo: Cortez; Brasília: SENEB, 1991. p. 51-64. 
MACHADO, L. R. S. Mudanças tecnológicas e a educação da classe trabalhadora. In: MACHADO, L. R. S. (Org.). Trabalho e educação. 2. ed. Campinas, SP: Papirus, 1994. p. 9-23.

MACIEL, A. C. Projeto Burareiro: politecnia e educação integral à luz da pedagogia histórico-crítica. In: SIMPÓSIO TRABALHO E EDUCAÇÃO, 4, 2007, Belo Horizonte. Anais do Simpósio: Gramsci, política e educação. Belo Horizonte: NETE/UFMG, 2007. p. 1-16.

MACIEL, A. C. A Escola Pública Frente às Políticas de Educação Integral: Alternativas à Crise Política Brasileira Atual. In: ENCONTRO ESTADUAL DA ASSOCIAÇÃO NACIONAL DE POLÍTICA E ADMINISTRAÇÃO DA EDUCAÇÃO Seção Amazonas, 4, 2017, Manaus. Anais do Encontro: políticas educacionais no Amazonas após 20 anos de LDB. Manaus: ANPAE, 2017. p. 1-12.

MACIEL, A. C. O projeto original. In: MACIEL, Antônio C.; BRAGA, Rute M.; RANUCCl, A. M. C. Projeto Burareiro de Educação Integral: original. Porto Velho: Temática, 2016.

MACIEL, A. C.; BRAGA, R. M. Projeto Burareiro: politecnia e educação integral à luz da pedagogia histórico-crítica. In: SANTOS, N. Alinhavos em ciências humanas. Porto Velho: EDUFRO, 2007. p. 59-74.

MACIEL, A. C.; BRAGA, R. M. Politecnia e emancipação humana: uma metodologia para a formação histórico-crítica na universidade (Volume 1). In: AMARAL, N. F. G.; BRASILEIRO, T. S. A. (Orgs.). Formação docente e estratégias de integração universidade/escola nos cursos de licenciatura. São Carlos: Pedro \& João; Porto Velho: EDUFRO, 2008. p. 203-217.

MACIEL, A. C.; BRAGA, R. M.; RANUCCl, A. M. C. Projeto Burareiro de Educação Integral: original. Porto Velho: Temática, 2016.

MACIEL, A. C. et al. (Orgs.). Currículo e metodologia da educação integral politécnica: aportes ao trabalho pedagógico coletivo. Porto Velho: Temática, 2016.

MACIEL, A. C.; JACOMELI, M. R. M.; BRASILEIRO, T. S. A. Fundamentos da educação integral politécnica: da teoria à prática. Educação \& Sociedade, v. 38, n. 139, p. 473-488, abr./jun. 2017.

MANACORDA, M. A. Marx e a pedagogia moderna. 2. ed. Campinas, SP: Alínea, 2010.

MARX, K. Instructions pour les délégués du Conseil central provisoire à propos de diverses questions. In: MARX, K.; ENGELS, F. Critique de l'éducation et de l'enseignement: une anthologie de Marx-Engels sur l'éducation, l'enseignement et la formation professionnelle. Introduction, traduction et notes de Roger Dangeville. 1976. Disponível em: <https://www.marxists.org/francais/marx/works/00/enseignement/critique_ enseignement.pdf>. Acesso em: 19 abr. 2017.

MARX, K. Instructions for the delegates of the Provisional General Council: the different questions. The International Workingmen's Association, 1866. 1996. Disponível

em: 
<https://www.marxists.org/archive/marx/works/1866/08/instructions.htm>. Acesso em: 18 abr. 2017.

MARX, K. Instruções para os delegados do Conselho Geral Provisório: as diferentes questões. Lisboa: Editorial Avante; Moscovo: Edições Progresso, 1982.

MARX, K. Instruções aos delegados do Conselho Central Provisório. In: MORAES (Ed.). Marx \& Engels: Textos sobre educação e ensino. Introdução e notas do Editor. São Paulo: Moraes, 1983. p. 2-8.

MARX, K. Las luchas de clases em Francia de 1848 a 1850. Moscú-URSS: Editorial Progreso, 1979a.

MARX, K. Crítica del programa de Gotha. Moscú-URSS: Editorial Progreso, 1979b.

MARX, K.; ENGELS, F. La revolución em España. Moscú-URSS: Editorial Progreso, 1974.

MARX, K.; ENGELS, F. Manifesto do Partido Comunista. In: ALMEIDA, J.; CANCELLI, V. (Orgs.). 150 anos de Manifesto Comunista. São Paulo: Xamã, 1998.

MARX, K.; ENGELS, F. Manuscritos econômico-filosóficos. In: MORAES (Ed.). Marx \& Engels: Textos sobre educação e ensino. Introdução e notas do Editor. São Paulo: Moraes, 1983. p. 33.

MORAES (Ed.). Marx \& Engels: Textos sobre educação e ensino. Introdução, apresentação e notas do Editor. São Paulo: Moraes, 1983. p. 8-14.

NOGUEIRA, M. A. Educação, saber, produção em Marx e Engels. São Paulo: Cortez, 1990.

NOSELLA, P. A escola de Gramsci. 3. ed. São Paulo: Cortez, 2004.

NOSELLA, P. Trabalho e perspectivas de formação dos trabalhadores: para além da formação politecnia. Revista Brasileira de Educação, v. 12, n. 34, p. 137-151, jan./abr. 2007.

NOSELLA, P. Ensino médio: em busca do princípio pedagógico. Brasília, DF: Portal MEC, 23 set. $2009 . \quad$ Disponível em: <http://portal.mec.gov.br/index.php?option=com_docman\&view=download \&alias=1732-ensino-medio-embuscadoprincipio\&ltemid=30192>. Acesso em: 21 set. 2014.

PEREZ, C. Microeletrónica, ondas largas Y cambio estructural mundial: nuevas perspectivas para los países en desarrollo. Londres: Science Policy Research Unit- SPRU/ Universidad de Sussex, 1984.

SANFELICE, J. L. A politecnia no ensino médio. In: BRASIL. Ministério da Educação. Secretaria Nacional de Educação Básica. Politecnia no ensino médio. Cadernos SENEB 5. São Paulo: Cortez; Brasília: SENEB, 1991. p. 65-72.

SAVIANI, D. Sobre a concepção de politecnia. Rio de Janeiro: EPSJV/Fiocruz, 1989. 
SAVIANI, D. O choque teórico da politecnia. Trabalho, Educação e Saúde, v. 1, n. 1, p. 131-152, 2003.

SAVIANI, D. Trabalho e educação: fundamentos ontológicos e históricos. Revista Brasileira de Educação, v. 12, n. 34, p. 152-165, jan./abr. 2007.

SILVA, C. A. da. O sistema público de educação de tempo integral em Manaus e as possibilidades da educação integral politécnica. 2017. $205 \mathrm{f}$. Dissertação (Mestrado em Educação) - Universidade Federal de Rondônia, Porto Velho, 2017.

SOARES, R. D. Gramsci, o Estado e a escola. ljuí, RS: UNIJUÍ, 2000.

SOARES, R. D. Entrevista com Mario A. Manacorda. Novos Rumos, Instituto Astrogildo Pereira, ano 19, n. 41, p. 3-23, 2004.

TEIXEIRA, E. de A. Contribuições da psicologia histórico-cultural para a coordenação da educação integral politécnica. 2017. 119 f. Dissertação (Mestrado em Educação) - Universidade Federal de Rondônia, Porto Velho, 2017.

Recebido em: Dezembro de 2017

Aprovado em: Março de 2018 